\title{
A Opacidade nas Relações Estabelecidas entre o Setor Privado e a Educação Pública Estadual de Mato Grosso
}

\author{
The Opacity in the Relations between the Private sector and Public education \\ of Mato Grosso State (Brazil)
}

\section{La Opacidad en las Relaciones Establecidas entre el Sector Privado y la Educación Pública de Mato Grosso (Brasil)}

\author{
Maria Clara Ede Amaral' \\ Regiane Helena Bertagna" \\ 'Secretaria de Estado da Educação de Mato Grosso (CEFAPRO/SEDUC/MT) MT - Brasil - email \\ claraede@gmail.com \\ "Universidade Estadual Paulista (UNESP) SP - Rio Claro - Brasil email - regiane@rc.unesp.br
}

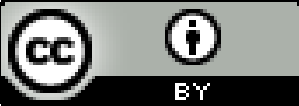

Educação: teoria e prática, Rio Claro, SP, Brasil - eISSN: 1981-8106

Está licenciada sob Licença Creative Common

\section{Resumo}

Com a disseminação dos preceitos neoliberais, a partir da década 1990, as parcerias públicoprivadas na área educacional se intensificaram no Brasil. A atuação de Organizações Não Governamentais e/ou Organizações Sem Fins Lucrativos desencadeou, em governos estaduais e municipais, a procura por meios de melhorar a qualidade das escolas de maneira aligeirada, com vistas à elevação dos índices na avaliação em larga nacional. O objetivo deste trabalho é analisar a relação entre duas organizações privadas - a Fundação CESGRANRIO (CES) e o Instituto Ayrton Senna (IAS) - com o governo estadual de Mato Grosso, por meio da análise da fala dos participantes da pesquisa e suas percepções quanto às informações sobre as parcerias, no período de 2006-2008. Foram sujeitos da pesquisa profissionais que atuaram nas redes de ensino dos municípios de Cuiabá e Cáceres, a saber: gestores, coordenadores pedagógicos e professores, profissionais da Secretaria de Estado de Educação de Mato Grosso - SEDUC/MT. Observa-se a crescente adesão a modelos privados na educação pública, por meio de organizações que introduzem o modelo de administração empresarial, que, por sua vez, influencia o funcionamento das redes públicas a partir da lógica de mercado, e, muitas vezes, alicerçadas em transações comerciais opacas e não transparentes, ferindo o princípio federal da Transparência Pública e as relações sociais e escolares.

Palavras-chave: Parcerias Público-Privada. Transparência Pública. Controle Social. Avaliação em larga escala. 


\begin{abstract}
The public-private partnerships in educational area were intensified, in Brazil, from the 90's with the spread of neoliberal precepts. The activities of non-governmental organizations and/or non-profit organizations unleashed in State and local governments a demand by means of fast improving the quality of schools, aiming to lifting the indices in large-scale assessment. This paper aims to analyze the relationship between two private organizations CESGRANRIO Foundation (CES) and Ayrton Senna Institute (IAS)- and the Government of Mato Grosso State, through the analysis of research participants' speech and their perceptions about access to information on these partnerships, from 2006 to 2008. The subjects were managers, education administrators and teachers who worked in schools in the municipalities of Cuiabá and Caceres, that is, professionals of Secretariat of Public Education of Mato Grosso State - SEDUC/MT. It is possible to note the increasing membership to private models in public education, through organizations that introduce the business management model, which in turn influences the operation of public networks from market logic, and often based on opaque and non-transparent commercial transactions, injuring the federal principle of Public Transparency and the social and school relations.
\end{abstract}

Keywords: Public-Private Partnerships. Public Transparency. Social Control. Large-scale assessment.

\title{
Resumen
}

Con la difusión de los preceptos neoliberales, desde finales de 1990, las asociaciones público-privadas en la educación se intensificaron en Brasil. La actuación de Organizaciones no Gubernamentales y/o sin Fines de Lucro, provocaron en los gobiernos estatales y locales la fuerte demanda de las formas de mejorar la calidad de las escuelas en forma más ligera, con miras a las crecientes tasas de Evaluación en gran escala. El objetivo es analizar la relación entre dos organizaciones privadas - Fundación Cesgranrio (CES) y el Instituto Ayrton Senna (IAS) - con el gobierno del estado de Mato Grosso, a través del análisis de la opinión de los participantes en la investigación y sus percepciones sobre las informaciones sobre las parejas, entre los años de 2006 a 2008. Fueran sujetos de la investigación profesionales que actuaron en este sistema escolar en las ciudades de Cuiabá y Cáceres: gerentes, coordinadores y maestros, profesionales de la Secretaría de Estado de Mato Grosso Educación - SEDUC / MT. Observase el aumento de la adhesión a los modelos privados en la educación pública, a través de las organizaciones que introducen el modelo de gobierno corporativo, que a su vez influye en la explotación de redes públicas de la lógica del mercado y con frecuencia apoyadas en transacciones comerciales opacas y poco transparentes, lesionando el principio federal de Transparencia Pública y de las relaciones sociales y escolares.

Palabras-clave: Asociaciones público-privadas. Transparencia Pública. Control Social. Evaluación en gran escala.

\section{Introdução}

A lógica de organização político-econômica e social que se instaurou no Brasil, a partir da década de 1990, baseada no neoliberalismo e resultante de um processo histórico iniciado quase três décadas antes, foi facilitadora de iniciativas do setor privado que passaram a interferir, de maneira mais incisiva, nos assuntos estatais. 
O debate mais amplo acerca da dicotomia público/privado não é recente. No Brasil, como indica Cury $(2008$, p. 3) já havia a indicação, por meio do decreto assinado por D. João VI, em 1821, de dois sujeitos que poderiam cuidar da educação escolar no país: o Estado e a iniciativa privada.

Daquele período até os dias atuais, os debates e embates vêm se modificando de acordo com as configurações distintas que a sociedade assume, com a especificidade de cada momento histórico. A discussão ao longo do tempo, dentro da perspectiva crítica da Educação, passa por um aspecto que se mantém e, por sua vez, nos é muito caro: a necessidade de garantia da cidadania por meio da educação, por ser esta um direito inalienável, que deveria ser garantido pelo Estado, por seu caráter de instituição que visa o bem comum, público, coletivo, aberto a qualquer pessoa e não por instituições que visam às necessidades e interesses (apenas) individuais (CURY, 2008).

Entretanto, Sanfelice (2005, p. 178) nos alerta para o fato de que grande parte do debate acerca do público/privado, como categorias correlatas e indissociáveis entre si (SAVIANI, 2005), passa pela concepção consagrada historicamente de que educação pública é sinônimo de educação estatal. Sanfelice (2005, p.179) afirma que: "rigorosamente [...] escola estatal não é escola pública a não ser no sentido derivado pelo qual o adjetivo 'público' se relaciona ao governo de um país ou estado: o poder público”. Isso ocorre porque o Estado, "com sua 'autonomia relativa', nem sempre age em função dos interesses comuns, já que estes, numa sociedade capitalista, jamais serão universalmente comuns".

Oliveira (2005, p. 158) destaca que a legislação brasileira sempre tratou o termo público como estatal. Nesse sentido, faz-se necessário distinguir que utilizamos o termo educação pública como educação sob a responsabilidade do Estado, de caráter estatal. $\mathrm{O}$ termo educação privada é utilizado, aqui, para organizações ${ }^{1}$ do setor empresarial, com caráter particular, privado. Nesse caso, apoiados no texto da Lei de Diretrizes e Bases da Educação Nacional no 9304/96 (BRASIL, 1996), que, em seu artigo 20, explicita os tipos de organizações privadas em: "particulares, comunitárias, confessionais e filantrópicas".

As organizações que são objeto deste trabalho, quais sejam a Fundação CESGRANRIO (CES) e Instituto Ayrton Senna (IAS), se localizam, nos termos da LDB 9394/96, na categoria de privadas/filantrópicas. De acordo com Oliveira (2005), no texto da Constituição Federal de 1988, estas são classificadas como privadas "sem fins lucrativos" de cunho "não-estatal”. Estas se enquadram na definição de organizações privadas, mas com a especificidade de corrente político-ideológica que ganha grande projeção nas reformas neoliberais, passando a orientar as ações do Estado - a Terceira Via, que entre outros aspectos, propõe a atuação do Terceiro Setor em substituição ao papel do Estado.

Para Oliveira (2005), a legislação brasileira apresenta uma variedade conceitual que:

\footnotetext{
${ }^{1}$ Quando nos referimos ao IAS, à CESGRANRIO e outros representantes do Terceiro Setor, optamos por utilizar o termo organizações no lugar de instituições, baseados em CHAUI (2003, p.6) que destaca: "A instituição social aspira a universalidade. A organização sabe que sua eficácia e seu sucesso dependem de sua particularidade. Isso significa que a instituição tem a sociedade como seu princípio e sua referência, num processo de competição com outras que fixam os mesmos objetivos particulares”.
} 
[...] além de explicitar um problema teórico relevante, reflete o complexo embate em torno do capítulo de educação do texto constitucional que, ainda que de forma mais matizada do que a proposta pelos setores confessionais, consagrou a possibilidade de existência de formas intermediárias entre o público e o privado, em seu sentido tradicional (OLIVEIRA, 2005, p. 163).

A Terceira Via é baseada no new labor de Tony Blair, a partir das reformas neoliberais de Margareth Thatcher, e tem Antony Giddens como um dos principais teóricos, que assim explica:

[...] a terceira via se refere a uma estrutura de pensamento e de prática política que visa adaptar a social-democracia a um mundo que se transformou fundamentalmente ao longo das últimas duas ou três décadas. É uma terceira via no sentido de que é uma tentativa de transcender tanto a social-democracia do velho estilo quanto o neoliberalismo (GIDDENS, 2000, p. 36).

Adrião e Peroni (2005, p.141) contribuem para o entendimento da dimensão da instauração da Terceira Via na sociedade, ao argumentarem que essa nova organização, pressupunha "novos interlocutores, ou melhor, de novos parceiros na oferta e manutenção das políticas sociais. Tais parceiros, identificados em segmentos da sociedade civil, comporiam o que entendemos por terceiro setor".

A inserção da sociedade civil nos assuntos antes relacionados ao Estado ou à esfera privada é analisada por Costa (2011) sob a perspectiva do texto de Giddens. A autora afirma que:

As transformações no papel do Estado apontam nova dimensão para a sociedade civil, ou sociedade civil ativa. Para a Terceira Via, é fundamental que a construção do "novo Estado democrático" implique também a renovação e o reordenamento da sociedade civil. "A sociedade civil ativa se tornaria locus da ajuda mútua, da solidariedade, da colaboração e da harmonização das classes sociais" (Ibidem, p.53). Para a Terceira Via, "o governo pode e deve desempenhar um importante papel na renovação da cultura cívica" da sociedade civil (GIDDENS, 2001, p.89), qual seja encaminhar a sociedade civil a partir de certas diretrizes. Isso demandaria que: o Estado e a sociedade civil trabalhassem em parceria; o Terceiro Setor e as associações voluntárias assumissem funções de Estado; as comunidades fossem incentivadas à resolução de seus próprios problemas; e que houvesse um pacto social para busca de solução pacífica dos conflitos sociais (GIDDENS, 2001 apud COSTA, 2011, p. 56).

O Terceiro Setor é definido por alguns autores como sinônimo de sociedade civil ou como entidades filantrópicas e assistenciais (ADRIÃO; PERONI, 2005; PERONI, 2008; PERONI et al., 2009; PERONI; OLIVEIRA; FERNANDES, 2009; MONTAÑO, 2010). O que se observa, nesse cenário de reconfiguração do papel do Estado, é o crescimento do Terceiro Setor no sentido de se constituir como uma esfera de atuação que não é estatal, tampouco privada.

Montaño (2010) busca conceituar o termo de maneira crítica:

O (equivocado) conceito de "terceiro setor" [...] não se deveria referir a organizações em determinado setor, mas uma função social, que passa a ser desenvolvida, agora sim, por organizações da sociedade civil e empresariais, e não mais pelo Estado [...]. Desta forma, o que é chamado "terceiro setor", numa perspectiva crítica e de totalidade, refere-se a um fenômeno real, ao mesmo inserido e produto da reestruturação do capital, pautado nos (ou funcional aos) princípios neoliberais [...] (MONTAÑO, 2010, p. 186, grifo do autor). 
Nesse contexto, se fortalecem as chamadas parcerias público-privadas (ADRIÃO; PERONI, 2005, 2008, 2010, 2011; ADRIÃO, 2008; PERONI, 2008; PERONI et al., 2009), cuja tônica é a diminuição do papel do estado nos serviços, no caso, educacionais, através da transferência de recursos financeiros a entidades do Terceiro Setor, que passam a imprimir a lógica empresarial ao serviço público.

Surgem, assim, organizações privadas de natureza distintas, que se apresentam com a solução para as mazelas da educação pública. Estas, de acordo com Cardoso (2005, p. 81), representam uma "esfera privada (re) nova (da)", atuando a partir das relações entre os setores público, privado empresarial e privado não empresarial (como ONGs, fundações, institutos e movimentos da sociedade civil).

Desse modo, ocorre uma espécie de privatização disfarçada do setor educacional:

A brecha para a atuação de ONGs, organizações sociais, institutos e outros, será dada ainda pela implementação de organizações sociais públicas não estatais de direito privado. Ao criar uma distinção entre "público" e "público não estatal", diferenciando ambas da noção de "privado", criou-se uma esfera jurídica e ideológica confortável para que os partidos políticos, mesmo que de esquerda, uma vez no poder, defendam posições privatistas disfarçadas de públicas não estatais (FREITAS, 2011, p. 10).

As parcerias entre os setores público e privado ampliam sua inserção ao ganharem espaço legal em leis específicas como a Lei das Organizações Sociais (OS) - Lei no 9637/98 (BRASIL, 1998), a Lei das Organizações da Sociedade Civil de Interesse Público (OSCIP) Lei $n^{\circ}$ 9790/99 (BRASIL, 1999). Em 2004, as parcerias passam a ser controladas pela chamada Lei das Parcerias Público-Privadas (PPPs) - Lei no 11.079/2004 (BRASIL, 2004), que regulamenta o registro, controle e fiscalização das organizações não governamentais.

Nesse sentido, ganha força a lógica do mercado no campo educacional (POWER; WHITTY, 2003), sob a forma de quase mercado, explicado por Barroso (2005) como a transformação do serviço público em serviço para clientes.

Por sua vez, Souza e Oliveira (2003, p. 10) destacam que: "a noção de quase mercado, tanto do ponto de vista operativo, quanto conceitual, diferencia-se da alternativa de mercado propriamente dita, podendo, portanto, ser implantada no setor público sob a suposição de induzir melhorias". Assinalam, ainda, que:

O recurso ao conceito de quase-mercado para interpretar as modificações em curso na educação pública permite-nos compreender a aplicação, na gestão dos sistemas educacionais, dos princípios e valores da iniciativa privada, que trazem consigo um projeto de sociedade que certamente não contém a utopia da transformação. Sem dúvida, a avaliação é um processo capaz de direcionar projetos e ações e o que se evidencia com as práticas em curso é a perspectiva da reprodução e intensificação das desigualdades educacionais e sociais (SOUZA; OLIVEIRA, 2003, p. 10).

No caso das redes de ensino (públicas) que trazem a iniciativa privada para dentro de sua organização, seja como forma de modificação da gestão da educação escolar, na compra de apostilas para os alunos (BERTAGNA; BORGHI, 2011) ou na contratação de capacitação aos professores, o que se configura é a lógica de prestação de serviços pautada nos preceitos do mercado, do quase-mercado, da competitividade, da eficiência e da produtividade (TIRAMONTI, 1997). 
Ao transferir para organizações do Terceiro Setor a responsabilidade pela organização da gestão e/ou pelos processos pedagógicos de uma determinada rede de ensino, como no caso de Mato Grosso, foco deste trabalho, instala-se, na rede em questão, uma lógica de organização educacional pautada nas relações de sucesso, fracasso e competitividade, dentro de padrões pré-estabelecidos pelo setor privado, apoiados na lógica empresarial e de mercado.

A discussão público/privado no Brasil, especificamente na área educacional, é objeto de incessantes pesquisas, com objetivos que possuem particularidades, mas que, de maneira geral, se aproximam por buscarem mapear, entender e analisar criticamente a inserção da iniciativa privada dentro do setor público e sua consolidação. Neste trabalho delineia-se, como objetivo principal, analisar a relação entre duas organizações privadas - a Fundação CESGRANRIO (CES) e o Instituto Ayrton Senna (IAS) - com o governo estadual de Mato Grosso, por meio da análise da fala dos participantes da pesquisa e suas percepções quanto às informações sobre as parcerias. Os sujeitos da pesquisa foram os profissionais que atuaram nas redes de ensino dos municípios de Cuiabá e Cáceres, no período de 2006 a 2008, a saber: gestores, coordenadores pedagógicos e professores, profissionais da Secretaria de Estado de Educação de Mato Grosso - SEDUC/MT e do Centro de Formação e Atualização dos Profissionais da Educação - CEFAPRO.

Na pesquisa, de cunho qualitativo (BOGDAN; BIKLEN, 1994),foram realizadas 31 entrevistas individuais(MANZINI, 2004) e com três grupos focais (DESLANDES, 2005; GATTI, 2005; BAUER, 2007), as quais foram gravadas e transcritas, na íntegra, para análise, além das anotações resultantes desse processo. Realizamos, assim, uma análise prévia (BARDIN, 2004), fazendo uma leitura flutuante dos dados, com o intuito de nos familiarizarmos com o material e partir para a análise mais detalhada, em busca de conceitos, categorias que pudessem emergir dos mesmos. Fez parte dos planos iniciais da pesquisa a Análise Documental dos contratos/convênios de parcerias, propostas pedagógicas e relatórios. Entretanto, a análise dos documentos nunca ocorreu, por total falta de acesso aos mesmos e, após várias tentativas frustradas, compreendeu-se ser este um dado ou um aspecto a ser considerado em relação à temática em estudo - a pouca transparência das relações estabelecidas entre o privado e o público.

\section{Transparência Pública e Controle Social das Parcerias: a}

\section{opacidade das relações}

Os documentos que formalizaram as parcerias entre as organizações e a Secretaria de Estado de Educação de Mato Grosso - SEDUC/MT fariam parte do escopo de análise da pesquisa. Além deles, propúnhamos a Análise Documental das Propostas Pedagógicas e Relatórios dos períodos em que as parcerias estiveram em vigor. Entretanto, não foi possível ter acesso a nenhum dos documentos. Realizamos inúmeras tentativas formais - junto à SEDUC-MT, CES, IAS e Tribunal de Contas de MT - e informais (SEDUC-MT, CEFAPROs de Cuiabá e Cáceres, profissionais entrevistados) para acessar os dados referentes aos contratos com as organizações privadas, sem sucesso. 
O inciso XXXIII do artigo $5^{\circ}$ da Constituição Federal estabelece que todo cidadão tem direito a amplo acesso às informações que sejam de seu interesse em relação aos órgãos públicos:

[...] todos têm direito a receber dos órgãos públicos informações de seu interesse particular, ou de interesse coletivo ou geral, que serão prestadas no prazo da lei, sob pena de responsabilidade, ressalvadas aquelas cujo sigilo seja imprescindível à segurança da sociedade e do Estado (BRASIL, 1988, s.p.).

A inacessibilidade aos documentos, que dão informações não apenas operacionais ou pedagógicas, mas também financeiras, impediu que exercêssemos o controle social que se baseia no direito ao acesso, à publicidade e compreensibilidade da informação. Platt Neto et al. (2006, p. 136) enfatiza a importância social da LRF - Lei de Responsabilidade Fiscal, pois esta: "se fundamenta em princípios como o planejamento, a transparência e participação popular. A participação popular depende fortemente da transparência das ações governamentais e das contas públicas".

No entanto, o que vivenciamos foi exatamente o contrário do que propõe a legislação citada acima. Para além da estranheza, a opacidade de tais informações causou grandes entraves para a pesquisa. Tivemos nossa trajetória metodológica comprometida e percebemos que o princípio da Transparência Pública não estava se aplicando ao caso das parcerias estudadas.

Segundo Arelaro (2008), a não transparência é característica das transações públicoprivadas, ainda que a iniciativa privada use como premissa a transparência como princípio da Administração Gerencial. Contudo, estabelecer um convênio entre a esfera pública e a privada requer seguir procedimentos específicos de licitação e prestação de contas. Trata-se de dinheiro público, sendo gasto à revelia da análise das instâncias competentes e conselhos de controle social, ações desenvolvidas sem a necessária regulamentação e a devida prestação de contas.

Santos e Oliveira (2013, p.128) investigaram a trajetória do conceito de controle social e consideram que essa noção é um instrumento fundamental na construção da cidadania ativa, que, segundo as autoras, "se inspira na estratégia política de que existe uma desigualdade cidadã, uma vez que, no Estado de direito, todos têm os mesmos direitos somente perante a Lei”. Trazendo para o contexto das relações de cunho público-privado, que se intensificaram no Brasil a partir da Constituição de 1988, bem como do Plano Diretor da Reforma do Aparelho do Estado (BRASIL, 1995), as autoras assinalam que se instaura uma lógica em que o controle social passa a ser exercido pela sociedade civil, que se configura como:

[...] a esfera pública não-estatal, caracterizada pelo chamado terceiro setor, ou seja, uma forma de atividade social com trabalhos realizados no interior das Organizações Não-governamentais (ONGs) e outros organismos ou associações similares (SANTOS E OLIVEIRA, 2013, p. 131).

Concordamos com Gutierres e Costa (2013) quando, analisando as relações entre o financiamento da Educação e o controle social dos recursos mobilizados nas parcerias, enfatizam que a sociedade deve participar das ações públicas em todos os níveis. As autoras compreendem controle social como

[...] a participação da sociedade na formulação, no acompanhamento e verificação das ações da gestão pública na execução de suas políticas, avaliando seus objetivos, 
processos e efeitos, para o exercício efetivo de cidadania (GUTIERRES e COSTA, 2013, p. 64).

Pires (2009), ao estudar a configuração jurídica da relação público-privada entre o IAS e o município de Sapiranga/RS, destacou a necessidade de reflexão sobre o controle social e as parcerias público-privadas, visto que, mesmo com a existência de estruturas de controle como o Tribunal de Contas, estas podem ser ineficientes na publicidade necessária para informar a população. Foi possível perceber, também, que o instrumento que poderia ser um facilitador da transparência dessas relações, o site de Transparência Pública das esferas governamentais, não ofereceu, na época da pesquisa, informações sobre as parcerias em estudo.

Para a construção da pesquisa foram inúmeras as consultas realizadas nos sites das duas organizações, em busca de informações que pudessem esclarecer suas metas e objetivos. Estes foram encontrados em seus respectivos endereços eletrônicos ${ }^{2}$, entretanto, como essas organizações atuam em todo o território nacional, em diferentes frentes, nos dois casos conseguimos informações bastante genéricas. Realizamos consultas, também, no site da SEDUC/MT ${ }^{3}$, onde obtivemos apenas informações das notas de imprensa. Nesse sentido, ressaltamos que, para efeitos de uma pesquisa de cunho científico, as informações dispersas e generalistas encontradas nos respectivos sites não se constituíram em fontes fidedignas e seguras para que realizássemos a etapa de análise documental à qual nos propusemos.

Outra fonte, utilizada por nós para entender a intencionalidade dessas organizações, foram as relevantes pesquisas desenvolvidas por estudiosos do tema (ADRIÃO; PERONI, 2010, 2011, 2013; BERTAGNA; BORGHI, 2011; CAETANO, 2013; COSTA, 2011; PERONI, 2008; PERONI et al, 2009) relativas a diferentes estados do Brasil, que vem agregando importantes dados ao escopo analítico da interface entre público e privado na educação brasileira. Essas pesquisas, dentre outras, deram substancial suporte ao nosso campo teórico, mas, na questão específica dos termos de contratação das parcerias pela SEDUC/MT, não houve avanço.

Dessa forma, podemos indagar sobre até que ponto a falta de informações ocorre pela ineficiência do Estado ou por exigências das organizações privadas parceiras. O que se evidencia é que a relação do Terceiro Setor com a esfera pública parece não atender aos preceitos da Transparência Pública, dificultando à sociedade o acompanhamento de tais parcerias entre o setor privado e público na educação, o que também se apresenta em relação às falas dos participantes da pesquisa.

\section{As parcerias entre a Secretaria de Estado de Educação de Mato Grosso e as Organizações Privadas: a percepção dos sujeitos}

2 Tais informações constam em: <http://www.cesgranrio.org.br/institucional/atuacao.aspx >. Acesso em 22.12.2014; <http://senna.globo.com/institutoayrtonsenna/quem_somos/index.asp >. Acesso em 22.12.2014.

3 Tais informações constam em: <http://www.seduc.mt.gov.br/Paginas/Seduc-e-Instituto-Ayrton-Sennalan\%C3\%A7am-programa-Circuito-Campe\%C3\%A3o.aspx>. Acesso em 05.01.2015.

Educação: Teoria e Prática/ Rio Claro/ Vol. 25, n.50/ p. 517-532/ Set.-Dez. 2015. 
A contratação de organizações privadas pela Secretaria de Estado de Educação de Mato Grosso - SEDUC/MT, foco deste trabalho, ocorreu entre os anos de 2006-2008, envolvendo a CESGRANRIO e o Instituto Ayrton Senna.

A parceria estabelecida com a CESGRANRIO, intitulada Eterno Aprendiz - Avaliação de alunos do Ensino Fundamental e capacitação docente de Língua Portuguesa $e$ Matemática, consistiu num programa elaborado para a Secretaria de Estado de Educação de Mato Grosso - SEDUC/MT. A formação continuada teve carga horária total de 100 horas e se destinou aos professores de Língua Portuguesa e Matemática das escolas públicas estaduais, sendo estendida aos Pedagogos e Coordenadores Pedagógicos das escolas. A Fundação desenvolveu e distribuiu, a todos os cursistas, material didático em formato de manual, contendo um grande volume de exemplos e exercícios, que eram explorados nos seminários formativos ministrados por professores doutores nas respectivas áreas. A parceria teve duração de 12 meses (2006) e, pelas falas dos profissionais entrevistados, os mesmos não foram esclarecidos sobre esse prazo e se sentiram surpreendidos com o fim do projeto. Quando perguntados, durante a entrevista individual, se foram informados que a parceria seria finalizada, obtivemos respostas como: "Eu acho que não. Eu acho que eles devem ter pensado que o material estava ali, e na cabeça deles o professor devia continuar trabalhando"(CESGRANRIO, PROFESSOR3 ${ }^{4}$ ). "Não sei exatamente, não lembro, não sei se disseram para a gente que ia continuar e não continuou, ou se disseram que tinha acabado" (CESGRANRIO, PROFESSOR4).

A parceria entre a Secretaria de Estado de Educação de Mato Grosso - SEDUC e o IAS teve início em 2007, a partir de mais uma iniciativa da Secretaria em buscar meios de melhorar os índices de desempenho escolar do estado. Inicialmente, foram implantados os programas emergenciais Se Liga e Acelera Brasil. No ano de 2008, o Se Liga não foi renovado, passando a ser implantado o Circuito Campeão, de cunho preventivo, com estratégias de gerenciamento dos resultados da aprendizagem. A parceria perdurou entre os anos de 2007 e 2008.

Segundo a fala dos profissionais entrevistados individualmente, e também no contexto do grupo focal, o início das duas parcerias ocorreu de maneira difusa, ou seja, sem que houvesse um momento formal em que a Secretaria anunciasse qual a sua intenção ao firmar os convênios. Como se torna perceptível nos relatos aqui transcritos, tanto pessoas envolvidas diretamente com a gestão quanto professores tomaram conhecimento da mudança ocorrida quando esta já estava em andamento e, naquele momento, não tinham clareza sobre os objetivos das parcerias.

Sinceramente? Há várias intenções, talvez, no fundo, seja para fazer mudanças na educação, mas a não continuidade desse projeto me faz pensar que há outros interesses, talvez financeiros... (CESGRANRIO, PROFESSOR3).

$\mathrm{O}$ que eles nos disseram foi que era para melhorar o ensino-aprendizagem dos alunos. Estava baixo, e no meu modo de entender era para melhorar as notas da Prova Brasil (CESGRANRIO, PROFESSOR7).

Eu não tenho opinião formada a respeito dessa parceria, mas eu acho que era para atender o objetivo do governo, porque a gente trabalhou os textos de uma forma que

\footnotetext{
${ }^{4}$ Por questão ética os nomes dos participantes foram omitidos.

Educação: Teoria e Prática/ Rio Claro/ Vol. 25, n.50/ p. 517-532/ Set.-Dez. 2015.
} 
hoje é cobrada nos concursos que tem por aí. Para atender os eixos, as capacidades todas, naquele momento, as habilidades e competências, a gente não tinha noção do que era isso e com o Eterno Aprendiz, trouxe uma noção para o que é a Prova Brasil, o que é cobrado lá (CESGRANRIO, PROFESSOR8).

Devido ao grau de crianças que chegaram à quarta série sem saber ler e já estavam chegando muita criança na quarta série sem saber ler, sem saber escrever e sem saber fazer uma continha. Eu acredito que foi baseado nisso daí. Para tentar sanar um pouco essa dificuldade que tinha (IAS, PROFESSOR6).

É difícil dizer por que, porque nós não estávamos sabendo de nada quando fomos a Cuiabá. Eu penso que tenha mais a ver com a adequação dos índices de alfabetismo, que foi essa a intenção (IAS, COORD. PEDAG. 21).

Até alguns deles falavam que era uma forma de preparar o aluno para a Prova Brasil para ter resultados melhores, para melhorar os índices... a política de poder mostrar que o Brasil estava melhor... (CESGRANRIO, GRUPO FOCAL, PROFESSOR33).

A falta de transparência do processo de contratação das parcerias fica explícita pela escassez de informações e documentos que regulamentavam, ou deveriam regulamentar, a transação entre uma instituição pública e o setor privado. Como mencionado anteriormente, não foram fornecidos, para apreciação e análise, os termos de parceria, tampouco as orientações pedagógicas, relatórios ou quaisquer tipos de documentos que contivessem a formalização das parcerias e as diretrizes pedagógicas.

Para além de todas as negativas às solicitações de acesso aos documentos, foi possível perceber, nas falas dos entrevistados, dúvidas e, em muitas delas, ficava patente que não compreendiam as parcerias, e essa afirmação se aplica, inclusive, àqueles participantes que exerciam funções de gestão e que, consequentemente, estiveram à frente das ações realizadas durante a vigência da parceria.

Ao serem indagados sobre os motivos que levaram a SEDUC a encerrar os convênios, os entrevistados demonstraram não ter acesso às informações concretas que lhes explicassem o fim das parcerias. Pelos depoimentos dos entrevistados, as duas parcerias terminaram abruptamente. No caso da CESGRANRIO, um ex-gestor informou que a duração do convênio deveria ser de um ano letivo, ou seja, somente em 2006. Entretanto, isso não foi informado aos professores e equipes gestoras das escolas, como o excerto revela:

A Secretária de Educação na época ficava buscando alguma forma de melhorar os resultados. Nós estávamos em plena execução do Eterno Aprendiz, ela foi de novo para um encontro de Secretários de Educação, viu a propagando do IAS lá, perguntou para outros secretários e já chegou aqui com tudo contratado para o ano seguinte. E nós ainda estávamos acreditando que o trabalho com a CESGRANRIO ia continuar no ano seguinte (CESGRANRIO, GESTOR 17).

Destacamos um diálogo ocorrido no Grupo Focal IAS (profissionais que trabalharam com os programas do Instituto Ayrton Senna), em que os participantes expressam sua angústia a respeito da descontinuidade das políticas e da escassez de informações sobre as mesmas:

IAS_Coordenador Pedagógico 21: Parece que, todas as ações elas terminam com o ano letivo.

IAS_Professor24: É!

IAS_Coordenador Pedagógico 21: Começa outro ano tudo novo.

IAS_Gestor20: Tudo novo. 
IAS_Coordenador Pedagógico 21: Começar do zero de novo. Então assim parece que não tem continuidade das coisas.

IAS_Professor24: É uma visão que o ano que vem não continua...

IAS_Coordenador Pedagógico 21: É!

IAS_Gestor20: Ou como se tivesse que vir prontas.

A inconstância das políticas e, consequentemente, de algumas parcerias entre o setor público e o privado, conforme apresentado aqui, ilustra e aponta para a necessidade de se questionar a respeito de qual qualidade se produz por meio da descontinuidade do trabalho contratado e desenvolvido pelo setor privado na educação pública. Para além disso, o que questionamos é a crescente tendência da inserção da lógica gerencialista e mercadológica, características do setor privado, na educação pública. Essa lógica, alicerçada na falta de transparência nas ações, reforça e aprofunda as desigualdades socioeducativas, e imprime no discurso corrente que a boa educação vincula-se à iniciativa privada e que a qualidade se traduz apenas com a alta dos índices de proficiência nas Avaliações Externas, dificultando a participação e controle da sociedade.

\section{Considerações Finais}

Considerando-se o crescente aumento da inserção do setor privado na educação pública, por meio da fala dos profissionais da educação do SEDUC/MT se percebe que a relação entre duas organizações privadas - a Fundação CESGRANRIO (CES) e o Instituto Ayrton Senna (IAS) - com o governo estadual de Mato Grosso, embora tenham ocorrido de maneira diferenciada, revelaram que há pouco esclarecimento a respeito da sua constituição, bem como acesso a informações e documentos que formalizaram tais parcerias para os próprios profissionais da rede. $\mathrm{O}$ contato direto com as empresas ocorria pela formação ou pela própria realização do trabalho a ser executado, e não pela apresentação e envolvimento dos mesmos nas propostas contratadas a serem desenvolvidas, portanto, o pouco acesso às informações sobre a contratação e finalização das parcerias.

Dessa forma, tais dados nos remetem à discussão sobre a importância da transparência pública e, consequentemente, à real possibilidade do controle social, uma vez que a falta de acesso às informações não permitiu compreender a que se destina a proposta e se atende às necessidades da rede de ensino, muito menos qual o impacto desse tipo de parceria e do trabalho contratado na qualidade que se pretende para a rede contratada.

Nesse sentido, é importante destacar que muitos dos participantes da pesquisa indicaram que um forte motivador para contratação de serviços privados estava associado à elevação dos índices de desempenho escolar do estado na avaliação em larga escala nacional.

Além disso, consideramos que é preciso ampliar essa discussão, enfocando que qualidade da educação não significa, apenas, obtenção de um bom índice ou proficiência em testes padronizados; estes são um dos indicadores para balizar as decisões políticas sobre a qualidade de uma dada rede, de uma instituição, mas, isoladamente, não representam a qualidade (social) necessária para relativa à educação que é um direito dos cidadãos.

Como bem afirmam os profissionais da rede, participantes deste estudo, pouco se sabe sobre o início e o término e, principalmente, a que vieram tais parcerias. As informações eram 
difusas, segundo relatos dos participantes, e não permitiam aos mesmos a clareza necessária em relação à proposta e às parcerias firmadas pelo governo, e, uma vez que o registro ou documentação dessas relações não estão disponíveis para consulta, dificulta-se à sociedade (civil) a participação e acompanhamento das parceiras entre o setor público e privado local.

A falta de clareza explicitada nas falas dos entrevistados, a respeito do processo que envolve a mudança na organização do trabalho pedagógico que representa a entrada da iniciativa privada na educação pública, se constituiu em um importante dado que denuncia a necessidade crescente da intencionalidade dessas parcerias e, no limite, quando ocorrerem, que sejam feitas às claras, de forma transparente e objetiva para o acompanhamento da sociedade civil.

É preciso ressaltar, igualmente, que este trabalho procura discutir a relação públicoprivada na área da Educação, estando as pesquisadoras guiadas pela ânsia da concretização de uma educação pública, gratuita, universal e de qualidade social (para todos).

\section{Referências}

ADRIÃO, T. Oferta do Ensino Fundamental em São Paulo: Um novo modelo. Educação e Sociedade, Campinas, v. 29, n. 102, p.79-98, Jan./Abr. 2008.

ADRIÃO, T.; PERONI, V. (Orgs.). O público e o privado na educação - interfaces entre estado e sociedade. São Paulo: Xamã, 2005.

ADRIÃO, T.; PERONI, V. (Orgs.). Público e o Privado na Educação: novos elementos para o debate. São Paulo: Xamã, 2008.

ADRIÃO, T.; PERONI, V. Análise das consequências de parcerias firmadas entre municípios brasileiros e a Fundação Ayrton Senna para a oferta educacional. Relatório de pesquisa. Campinas/SP. CNPq, 2010.

ADRIÃO, T.; PERONI, V. Consequências da atuação do Instituto Ayrton Senna para a gestão da Educação Pública: observações sobre 10 estudos de caso. Práxis Educativa, Ponta Grossa, v.6, n.1, p.45-53, jan./jun., 2011.

ADRIÃO, T.; PERONI, V. (Orgs.). Gestão municipal da educação e as parcerias com o Instituto Ayrton Senna. Goiânia: Funape/Recife: ANPAE, 2013.

ARELARO, L.G. A não-transparência nas relações público-privadas: o caso das creches conveniadas. In: ADRIÃO, T.; PERONI, V.(Orgs.). Público e o Privado na Educação: novos elementos para o debate. São Paulo: Xamã, 2008, p. 51-66.

BARDIN, L. Análise de Conteúdo. 4 ed. Lisboa: Editora 70, 2004.

BAUER, M. W.; GASKELL, G. Pesquisa qualitativa com texto, imagem e som: um manual prático. Petrópolis: Vozes, 2007.

BARROSO, J..O Estado, a Educação e a Regulação das Políticas Públicas. Educação \& Sociedade, Campinas, v. 26, n. 92 - Especial, p. 725-751, Out. 2005. 
BERTAGNA, R. H.; BORGHI, R. F. Possíveis relações entre avaliação e sistemas apostilados privados em escolas públicas. Educ. Teoria Prática, Rio Claro, v.21, n.38, p.132-146, Dez. 2011.

BOGDAN, R.; BIKLEN, S. K. Investigação qualitativa em educação: uma introdução a teoria e aos métodos. Porto: Porto Ed., 1994.

BRASIL. Constituição da República Federativa do Brasil: promulgada em 5 de outubro de 1988. Brasília, DF: Senado, 1988.

BRASIL. Plano Diretor da Reforma do Aparelho do Estado. Brasília: Ministério da Administração e Reforma do Estado (MARE), 1995.

BRASIL. Lei n. 9.394, de 20 de dezembro de 1996. Dispõe sobre as Diretrizes e Bases da Educação Nacional. Diário Oficial da União. Brasília, DF: 21 de dezembro de 1996.

BRASIL. Lei no 9637, de 15 de maio de 1998. Dispõe sobre a qualificação de entidades como organizações sociais, a criação do Programa Nacional de Publicização, a extinção dos órgãos e entidades que menciona e a absorção de suas atividades por organizações sociais, e dá outras providências. Brasília: Casa Civil, 1998. Disponível em:

<http://www.planalto.gov.br/ccivil_03/LEIS/L9637.htm>. Acesso em: 13 dez. 2015.

BRASIL. Lei no 9790, de 23 de março de 1999. Dispõe sobre a qualificação de pessoas jurídicas de direito privado, sem fins lucrativos, como Organizações da Sociedade Civil de Interesse Público, institui e disciplina o Termo de Parceria, e dá outras providências. Brasília: Casa Civil, 1999. Disponível em:<http://www.planalto.gov.br/ccivil_03/LEIS/L9790.htm>. Acesso em: 13 dez. 2015.

BRASIL. Lei $\mathbf{n}^{\mathbf{0}}$ 11.079, de 30 de dezembro de 2004. Institui normas gerais para licitação e contratação de parceria público-privada no âmbito da administração pública. Brasília: Casa Civil, 1999. Disponível em: <http://www.planalto.gov.br/ccivil_03/_ato2004-

2006/2004/lei/111079.htm>. Acesso em: 13 dez. 2015.

CAETANO, M. R. Relações entre o público e o privado: a gestão pedagógica da educação no Programa Circuito Campeão do Instituto Ayrton Senna. In: SIMPÓSIO BRASILEIRO DE POLÍTICA E ADMINISTRAÇÃO DA EDUCAÇÃO, 26, Recife, 2013. Anais... Recife: ANPAE, 2013. p. 1-14. (Cadernos ANPAE, vol. 17).

CARDOSO, C. O público no privado e o privado no público em Portugal e na Inglaterra. In: ADRIÃO, T.; PERONI, V. (Orgs.). O público e o privado na educação - interfaces entre estado e sociedade. São Paulo: Xamã, 2005, p. 81-117.

CHAUI, M. A universidade pública sob nova perspectiva. Rev. Bras. de Educação, São Paulo, n.24, p. 05-15, set./out./nov./dez. 2003.

COSTA, M. de O. Concepções de gestão nos programas do Instituto Ayrton Senna no contexto de alterações no papel do estado e da sociedade civil. 2011. 346p. Tese

(Doutorado em Educação) - Universidade Federal do Rio Grande do Sul, Porto Alegre, 2011. 
CURY, C.R.J. Um novo movimento da educação privada. In: ADRIÃO, T.; PERONI, V.(Orgs.). Público e o Privado na Educação: novos elementos para o debate. São Paulo: Xamã, 2008. p 17-25.

DESLANDES, S. F. Trabalho de campo: construção de dados qualitativos e quantitativos. In: MINAYO, M. C. de S.; ASSIS, S. G. de; SOUZA, E. R. de (Orgs.). Avaliaçãa por triangulação de métodos: abordagem de programas sociais. Rio de Janeiro: FIOCRUZ, 2005, p. 157-184.

FREITAS, L. C. Responsabilização, meritocracia e privatização: conseguiremos escapar ao neotecnicismo? In: SEMINÁRIO DE EDUCAÇÃO BRASILEIRA, 3, Campinas, 2011. Anais do III Seminário de Educação Brasileira CEDES. Campinas: Unicamp/CEDES, 2011, p. 47-51.

FREITAS, L. C. Os reformadores empresariais da educação: da desmoralização do magistério à destruição do sistema público de educação. Educação \& Sociedade, Campinas, v. 33, n. 119, p. 379-404, Abr./Jun. 2012.

GATTI, B.A. Grupo focal na pesquisa em ciências sociais e humanas. Brasília: Liber Livro, 2005.

GIDDENS, A. A terceira via - reflexões sobre o impasse político atual e o futuro da socialdemocracia. $3^{\circ}$ ed. Rio de Janeiro: Record, 2000.

GUTIERRES, D.V.G.; COSTA, M. O financiamento e o controle social dos recursos da educação no contex to das parcerias firmadas entre o Instituto Ayrton Senna (IAS) e municípios brasileiros. In: ADRIÃO, T.; PERONI, V. (Orgs.). Gestão municipal da educação e as parcerias com o Instituto Ayrton Senna. Goiânia: FUNAPE/Recife: ANPAE, 2013, p. 60-81.

MANZINI, E. J. Entrevista semiestruturada: análise de objetivos e de roteiros. In: SEMINÁRIO INTERNACIONAL DE PESQUISA E ESTUDOS QUALITATIVOS, 2, Bauru, 2004. Anais... Bauru: Universidade Sagrado Coração, 2004. p.1-12. CD- Rom.

MONTAÑO, C. O terceiro setor e a questão social: crítica ao padrão emergente de intervenção social. 6 ed. São Paulo: Cortez, 2010.

OLIVEIRA, D. A. Regulação das políticas educacionais na América latina e suas consequências para os trabalhadores docentes. Educação \& Sociedade, Campinas, v. 26, n. 92- Especial, p. 753-775, Out. 2005.

PERONI, V. M. V. O público e o privado na gestão e financiamento de sistemas educacionais públicos: um estudo dos programas da Rede Vencer, coordenado pelo Instituto Ayrton Senna. In:

ALBUQUERQUE,M. G. M. T.; FARIAS,I. M.S. de; RAMOS,J. F. P. (Orgs.). Política e Gestão educacional: contextos e práticas. Fortaleza: Ed. UECE, 2008. 
PERONI, V. M. V.; OLIVEIRA, R. T. C.; FERNANDES, M. D. E. Estado e Terceiro Setor: as novas regulações entre o público e o privado na gestão da educação brasileira. Educação e Sociedade, Campinas, v. 30, n. 108, p. 761-778, Out. 2009.

PERONI, V.M.V. et al. Terceira Via, Terceiro Setor e a parcerias IAS/Sistemas de ensino público no Brasil. Educação: teoria e prática, Rio Claro, v.19, n. 32,p.17-35, 2009.

PIRES, D. de O. A configuração jurídica e normativa da relação público-privada no Brasil na promoção do direito à educação. 2009. 186 p. Dissertação (Mestrado em Educação) - Universidade Federal do Rio Grande do Sul, Porto Alegre, 2009.

PLATT NETO, O.A., et. al. Transparência das contas públicas: um enfoque no uso da internet como instrumento de publicidade na UFSC. Revista Contemporânea de Contabilidade, Florianópolis, Ano 3, v. 1, n. 5, p. 135-146, jan./jun, 2006

POWER, S.; WHITTY, G. Mercados Educacionais e a comunidade. Educação \&Sociedade, Campinas,v. 24, n. 84, p. 791-815, set, 2003.

SANFELICE, J. L. A problemática do público e do privado na história da educação no Brasil. In: Lombardi, J. C.; JACOMELI, M. R. M.; SILVA,T. M. T. da (Orgs.). O público e o privado na história da educação brasileira. Campinas: Autores Associados/Histedbr/UNISAL, 2005, p. 177-185.

SANTOS, T. F. A. M.; OLIVEIRA, R. T. C. O Controle Social e as Parcerias entre os Governos Municipais e o Instituto Ayrton Senna. In: ADRIÃO, T.; PERONI, V. M. (Orgs.). Gestão municipal da educação e as parcerias com o Instituto Ayrton Senna. Goiânia: Funape/Recife: Anpae, 2013, p. 126-145.

SAVIANI, D. O público e o privado na história da educação brasileira. In:Lombardi, J. C.; JACOMELI, M. R. M.; SILVA,T. M. T. da (Orgs.). O público e o privado na história da educação brasileira. Campinas: Autores Associados/Histedbr/UNISAL, 2005, p. 167-176.

SECRETARIA DE ESTADO DE EDUCAÇÃO DE MATO GROSSO SEDUC/MT/CEFAPRO/CÁCERES-MT. Projeto "Eterno Aprendiz" - notícias. Cáceres: SEDUC, 2006. Disponível

em: <http://www.seduc.mt.gov.br/conteudo.php?sid=20\&cid=4588\&parent=0>. Acesso em: 21 de setembro 2012.

SOUZA, S. Z. L. de; OLIVEIRA, R. P. de. Políticas de avaliação da educação e quase mercado no Brasil.Educação \& Sociedade, Campinas, v.4, n.84, p.873-895, Set. 2003.

TIRAMONTI, G. Los Imperativos de las Políticas Educativas de los 90. Revista da Faculdade de Educação da USP. São Paulo, v. 23, n. 1, p. 49-69, Jan./Dec. 1997. 
Recebido em: 25/02/2015

Revisado em: 30/09/2015

Aprovado para publicação em: 09/11/2015

Publicado em: 22/12/2015 